\title{
A Comparison of Competitive and Collaborative Play for Co-located Computer Supported English Vocabulary Learning
}

Paul Craig, Zeyang Jiang, Hai-ning Liang

Department of Computer Science and Software Engineering

Xi'an Jiaotong Liverpool University

China

\{P.Craig@xjtlu.edu.cn\}\{Zeyang.Jiang14@alumni.xjtlu.edu.cn\}\{HaiNing.Liang@xjtlu.edu.cn\}

\begin{abstract}
This paper compares different modes of competitive and collaborative play for co-located computer supported English vocabulary learning. To do this we have developed a video-game for learning vocabulary than can be played by two players sitting together by either working together and collaborating to improve their score or competing against each other to see who can achieve the best score. We evaluated these different collaborative and competitive game modes by asking ninety-six participants to complete a test before and after playing the games. Our participants were also asked to fill out a questionnaire and take part in a structured interview after playing the game. Results from this evaluation reveal that collaborative play is more effective than competitive play for helping students to achieve learning objectives, but neither type of play is effective as traditional learning using vocabulary leaning cards. Collaborative play was found to give around $56 \%$ the improvement of traditional learning with competitive play giving around 7\%. Collaborative play is also preferred by most students involved in the study, and the participants in our study considered that either type of game could play an important role to supplement traditional learning in a more relaxed and sociable environment.
\end{abstract}

Keywords: Educational Games, Co-located learning, Collaboration, Cooperation

Received: 13 July 2019, Revised 24 September 2019, Accepted 3 October 2019

(C) 2019 DLINE. All Rights Reserved

DOI: $10.6025 / \mathrm{jcl} / 2019 / 10 / 4 / 134-144$

\section{Introduction}

The past few decades have seen a rapid rise in the popularity of recreational video games. Indeed, it is estimated that at least $90 \%$ of American adolescents play video games an average of 2 hours each day and $25 \%$ play video games at least 4 hours a day [1]. As the time spent playing video games is often time taken away from other important activities, the overuse of video-games is certainly detrimental to the education and development of many young adults [2-5]. However, despite the negative aspects of video game overuse, the potential of video games to be used in education is also widely recognised [6].

There is much valuable research already into how we can make educational video games more effective. This research examines

134 International Journal of Computational Linguistics Research Volume 10 Number 4 December 2019 
topics such as the use of learning assistants [7, 8], location based gaming $[9,10]$ and gameplay elements [11]. This study aims to supplement this research by assessing the effect of different game mechanics for games that students play together in the same physical space. Specifically we are concerned with the effectiveness of foreign language vocabulary learning using games with either competitive or collaborative gameplay.

To achieve the objectives of our study to compare collaborative and cooperative gameplay in educational games we have developed a game for native Chinese speakers learning English vocabulary that can run either by rewarding collaboration, where students work together toward a common objective, or competition, where students work against each other to achieve individual objectives. To assess each mode of gameplay we compare the achievement of learning objectives before and after playing each type of game. We also ask our subjects to fill in a questionnaire and interview them to gauge their attitudes toward each type of game.

\section{Educational Games}

Educational games are video-games that can be used for learning. Kinzie et al. define a game as "an immersive, voluntary and enjoyable activity in which a challenging goal is pursued according to agreed-upon rules" [12]. With computer and communication technologies experiencing a rapid development and rise in popularity, it can be predicted that technology will be used more and more games and in learning. It follows that, educational video-games, which enable students to learn in an interactive learning environment, could be an important component of learning environments in the future [13].

Indeed, educational games have already proven effective in diverse areas such as mathematics [14, 15], computer science [16], software engineering [17, 18], civil engineering [19], geography [20], social science [21], business [22], language [23] and traditional science subjects [24]. Studies have shown that educational games have great potential to enhance students' learning achievement [25-27], learning interest [19,28] and learning motivation [28-31].

Collaborative and competitive gaming are of interest not only as aspects of gaming that can be used to make educational games more appealing to learners, but also as a way to help teach students 'soft' skills and encourage personal and social development. While many of the negative aspects of gaming are rooted in it being an intrinsically antisocial activity where players generally play with limited human contact, co-located collaborative and competitive games $[7,8]$ avoid these aspects and actually require people to interact in the same physical space. Indeed, there is a good deal of research looking at collaborative games [7, 8, 3236] and competitive games [37-39], but few studies that explicitly compare the two modes and none that compare the two for vocabulary learning.

\subsection{Vocabulary Learning}

When learning a foreign language, a great deal of time can be spent trying to develop a sufficient vocabulary in that language. This is especially the case when we try to learn a language that is significantly different from our own. If the new language being learnt is closely related to the learners native language then a lot of vocabulary can be carried over from the native language, so vocabulary learning is not such a problem. This is certainly the case with romance languages like Spanish and Italian where many words are similar or virtually the same. For example, the word message in English is mensaje in Spanish and messagio in Italian. This is similarity in vocabulary words is a lot rarer for unrelated languages such as Chinese and English (message is pronounced Xinx + in Chinese). This makes learning vocabulary for a language unrelated to your own very difficult and an increasing number of language learners need to do this. In fact, the greatest number of language learners today are the approximately 0.4 billion Chinese learning English [40]. So, learning vocabulary is a big issue.

It is estimated that there are 1.5 billion English language learners around the world [41]. The British Council estimated that 2 billion people will be learning English by 2020. Statistics indicated that more than 0.4 billion English language learners are Chinese by 2014, taking up approximately one third of the total number of Chinese citizens [40]. In fact, China has the largest number of people purchasing digital products to learn English. In China, digital products on English learning had a compound annual growth rate (CAGR) of $23.6 \%$ in past five years. Surprisingly, in the forecast period, its revenues will experience a nearly tripling from \$323.1 million in 2013 to $\$ 931.8$ million in 2018 [42].

Despite the amount of money spent by the Chinese on English learning, the results are surprisingly poor. China ranks only 29th out of 44 non-English-speaking countries or regions, and is the second worst out of all Asian countries (only slightly ahead of Thailand) [43]. 
To learn English well, a second language learner needs to build a vocabulary of at least 5000 words and preferably 10000 words [44]. Vocabulary games are a good way to promote vocabulary learning and motivate English language learners and when developing this sort of game it is important to take into account some prominent theories in the domain of vocabulary learning and teaching [44]. These include theories related to the integration of vocabulary with communication learning [45-47], meaning and form [46-48], and memory [49].

It also makes sense to consider the characteristics of learners that can influence game design. Topics should be familiar and the vocabulary being presented should reflect the age, gender, and level of the learner. We also need to consider that language learning requires memorization and that memorisation requires repetition to be effective. According to the Ebbinghaus Forgetting Curve proposed in 1985, learners forget vocabulary dramatically with only $33.7 \%$ of words being retained if they are not reviewed after one day. This rate of retention decreases over time.

So review is an important aspect of vocabulary learning and it is important to have alternative methods of vocabulary learning to try and prevent learning the same words from becoming too boring or monotonous for the learner. Collaborative and competitive vocabulary learning games are a way to introduce a social aspect into learning to engage students.

\subsection{Collaborative Educational Games}

Broadly speaking, collaboration is when two or more people work toward the same common objective. Collaborative learning is when two or more people learn or attempt to learn something together [50]. This requires the mutual engagement of all participants and a coordinated effort to solve the problem [51-53]. Studies show that collaborative learning can help develop teamworking skills as well as associated learning objectives $[32,35,54,55]$. Collaborative learning is found to be particularly effective when the objective is to understand more difficult concepts or generate ideas [56].

Research indicates that collaborative educational games on both mobile and desktop devices have great potential to enhance students' learning performance and learning attitudes in multiple different subject areas [32, 35, 57-59]. For example, Fengfeng Ke et al. [35] examined the impact of how educational games helped fifth-graders' learn maths and developed their attitudes toward maths. Here, playing collaborative games was found to be better than traditional methods for learning maths and, despite individual differences among students, improved positive attitudes toward maths. In 2011, Hummel et al. [58] explored the extent by which playing serious games are able to improve student learning outcomes for applied science and found that collaborative learning approach considerably improved the quality of the learning outcomes. Sánchez et al. [59] implemented a series of Mobile Serious Games (MSGs) based learning activities on 10 Chilean 8th-grade classes from 5 different schools to foster their problem-solving and collaborative skills. The experimental results revealed that the mobile game-based collaborative learning approach significantly improved students' learning outcomes. In 2013, Sung and Hwang [32] conducted an experiment on three classes of 93 sixth graders attending natural science course in an elementary school and illustrated that collaborative educational game integrated with a knowledge sharing and organizing equipment-grid-based Mindtool using repertory grid method is beneficial to the students in enhancing their learning motivation and learning attitudes, as well as raising their self-efficacy and academic performance. This body of research demonstrates the potential of collaboration in educational videogames.

Other research explores the conditions to be set for effective group collaboration and looks at how best to support collaborative learning. Lou et al. [60] conducted a meta-analysis and found that in about $25 \%$ of research conducted collaboration did not have a significant effect on learning, and sometimes even had a negative effect. To make sure group collaboration has the desired effect, Slavin proposes a set of desirable conditions. Foremost of these is that all group members should be aware of a shared group goal that they consider significant. They also need to have the capability to make contributions to the success of the activity. Studies have also been conducted in order to find additional ways we can supporting group collaboration such as collaboration scripts, structuring the dialogue, visualization tools, managing the cognitive load, intelligent tutors and interactive dialogue agents [61-66].

Although collaborative learning can enhance students' academic performance and learning attitudes, according to Johnson's study in 1994 [67], moderating factors may affects the level of enhancement through collaborative learning. For example, in a previous study, students with relatively poor academic performance enhanced more than top students from collaborative learning and collaborative educational game [68]. In 1999, Jean et al. [69] found that more boys played collaborative educational game and solved problem in groups while girls had difficulty in recognizing the embedded maths elements in the game. Three years later, Moreno [70] found that visual representations in the game significantly helped low-achievement and less computer experience students. Socio-economic status (SES) may also mediate the effects of playing educational game [71]. Therefore,

136 International Journal of Computational Linguistics Research Volume 10 Number 4 December 2019 
prior academic performance and knowledge, prior computer experience and gender could mediate the effects of learning.

Researchers who have proposed guidelines or frameworks for designing collaborative games include Natalia Padilla Zea et al. [72] who designed a collaborative educational videogame for 3-4 year-old children and explored the utilization of videogames in the classroom. This group of authors presented a set of design guidelines incorporating the features of collaborative learning proposed by Johnson and Johnson including; Positive Interdependence, personal accountability, face-to-face promotive interaction, social skills and group processing in the designing process of videogame. They also examined the extent to which these guidelines impact the videogame architecture and the ways of which these guidelines be utilized when developing a videogame. Triantafyllakos et al. [73] proposed a framework for designing educational computer games collaboratively with involvement of students in game design sessions and conducted three studies to evaluate it. The result shows that the proposed framework is able to simplify the development and employment of effective and efficient collaborative game design activities in educational settings. Villalta et al. [74] presented guidelines for designing Classroom Multiplayer Presential Games (CMPG) on a screen projected at the front of the classroom, which are implemented through which the students interact collaboratively with the virtual world and among themselves in the shared space. Individual players control the representative characters using their own input devices in a CMPG activity.

\subsection{Competitive Educational Games}

Research into competitive educational games is somewhat less common than research into collaborative games. In one study Hung et al. proposed a collaborative and competitive game-based learning environment using a Wireless Crossword Fan-Tan Game (WiCFG) system to improve English proficiency [75]. This was based on groups competing against each other. An evaluation of this system found it was able to significantly enhance lower achieving students' learning achieving compared to the traditional learning method. There was no significant difference for high-achievement students. The game was also found to promote interaction between students with different English levels, and enhance their learning motivation and classroom engagement. So, when competitive games have been evaluated the overall effect has been found to be generally positive.

\section{Game Design}

The game we have developed for our study is an educational game for Chinese players to learn English vocabulary by matching English words to Chinese words. The game is a tower defence type game where players need to match English words correctly to increase their score and prevent enemies from advancing and draining their life force. The aim of the game is achieve the highest score possible before all the life force is drained.
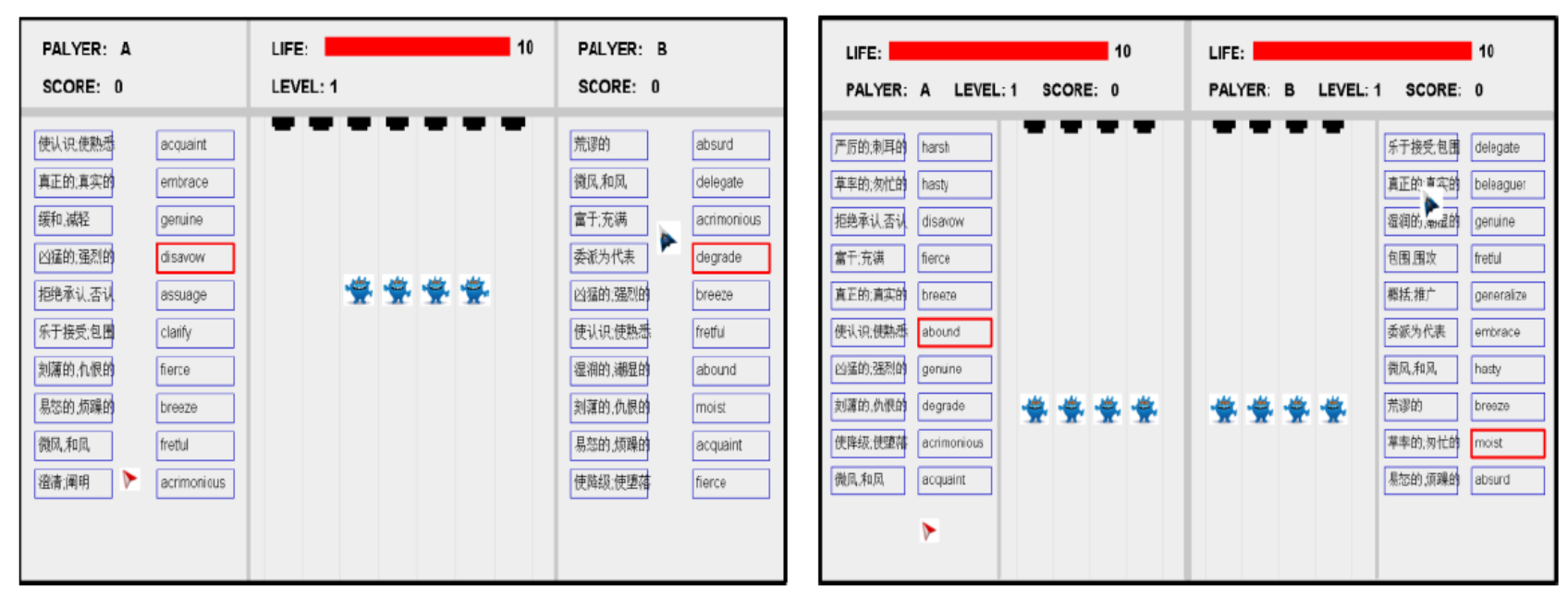

Figure 1. The vocabulary learning game running in (a) collaborative mode and (b) competitive mode

Figure 1a shows the game running in collaborative mode. In the centre of the screen are icons which represent monsters that advance toward the top of the screen to drain the players' life. The top left corner and top right corner of the screen display the name and score for each player as well as the level of difficulty and the amount of life level for the team. Below this are the pairs of English and Chinese words which each need to be matched in order to increase the score and repel the monsters to advance

International Journal of Computational Linguistics Research Volume 10 Number 4 December 2019 
in the game. The players are given the score and need to work together by matching words to advance and do well in the game. At the end of the game the players are shown a high score table showing how the performance of their team compares to that of others.

Figure $1 \mathrm{~b}$ shows the game running in competitive mode. This has approximately the same rules as the collaboration mode. The primary difference with this game is that the players work independently on different sides of the screen with separate scores and separate life levels. The player who finishes the ame with the higher score or passes all levels in shortest time is deemed to have won the game. At the end of the game the name of the winning player is displayed on the screen.

\section{Experimental Design}

In order to evaluate the different modes of play ninety-six students were drawn from three classes in with thirty-four year one undergraduate students, thirty-four year three undergraduate students and twenty-eight postgraduate students.

For the experiment, subjects were divided into experiment group and control group, with the former being subdivided into collaborative group and competitive group. The collaborative group learnt some vocabulary by playing the vocabulary educational game in collaborative mode while competitive group played the same game in competitive mode. Students in control group learnt vocabulary alone using the traditional method using cards with the Chinese and English words printed on either side.

Students in the experimental group were asked to sit in front of computers with each pair using one computer either in collaborative or competitive mode to play the game. All groups of participants were required to complete an English vocabulary test before and after playing the game as well as completing a questionnaire and being interviewed.

\section{Results}

The students' pre and post-test results, and their average vocabulary improvement in each grade using each learning method are presented in Table 1 . Here it can be seen that the students' average vocabulary improved significantly with the collaborative game group, while the competitive showed a relatively small improvement.

\begin{tabular}{|l|l|l|l|l|l|}
\hline Learning Method & Test & Grade & \multicolumn{3}{|c|}{ Overall } \\
\hline \multirow{4}{*}{ Collaborative game } & Pre-test & UG1 & UG3 & PG & \\
& Post-test & 8.75 & 6.17 & 8.6 & 6.021667 \\
& $\begin{array}{l}\text { Average } \\
\text { vocabulary } \\
\text { improvement }\end{array}$ & 4.75 & 8.33 & 20.9 & 14.24167 \\
& & & & 8.22 \\
\hline \multirow{2}{*}{ Competitive game } & Pre-test & 4.17 & 6.58 & 9.4 & 6.548958 \\
& Post-test & 6.5 & 9.5 & 13.2 & 9.516667 \\
& Average & 2.33 & 2.92 & 3.8 & 2.967708 \\
& vocabulary & & & & \\
& improvement & & & & \\
\hline Traditional Learning & Pre-test & 4.2 & 6.9 & 9.25 & 6.629167 \\
& $\begin{array}{l}\text { Post-test } \\
\text { Average } \\
\text { vocabulary } \\
\text { improvement }\end{array}$ & 18.3 & 21.5 & 24.88 & 21.3525 \\
& & & & & \\
& & & & & \\
\hline
\end{tabular}

Table 1. Participants' pre and post-test results and their average vocabulary improvement in terms of grade and learning method 
One-way ANOVA was used to see whether the interaction between groups and students' pre-test results was significant. The significant values of this kind of interaction for year 1 , year 3 undergraduates and postgraduates were larger than 0.05 with 0.268 , 0.972 and 0.134 respectively, which showed that groups had no statistically significant interaction with students' pre-test results. In other words, all groups were homogenous in terms of their prior vocabulary knowledge and thus got similar pre-test results. This meant that analysis-of-covariance (ANCOVA) could be conducted to further analyse the data.

\begin{tabular}{|l|l|l|l|l|c|}
\hline Grade & Group & $\mathbf{N}$ & Mean & S.D. & Adjusted mean \\
\hline \multirow{3}{*}{ UGYear1 } & Collaboration & 12 & 8.50 & 2.970 & 8.716 \\
& Competition & 12 & 6.50 & 2.714 & 6.394 \\
& Individual rote & 10 & 18.30 & 2.627 & 18.168 \\
& Collaboration & 12 & 14.50 & 4.642 & 14.904 \\
\hline \multirow{2}{*}{ UGYear3 } & Competition & 12 & 9.50 & 3.090 & 9.440 \\
& Individual rote & 10 & 21.50 & 3.240 & 21.087 \\
& Collaboration & 10 & 20.90 & 4.654 & 21.278 \\
\hline PG & Competition & 10 & 13.20 & 3.615 & 12.936 \\
& Individual rote & 8 & 24.88 & 3.603 & 24.732 \\
& & & & & \\
\hline
\end{tabular}

Table 2. Descriptive data and the ANCOVA result of students' post-test for the three groups

\begin{tabular}{|l|l|l|l|c|}
\hline \multirow{2}{*}{ Learning methods } & UGYear1 & UGYear3 & PG & Sig. \\
\cline { 2 - 5 } & .024 & .000 & .000 & .000 \\
\hline Collaboration Vs Control group & .000 & .000 & .048 & .000 \\
\hline Competition Vs Control group & .000 & .000 & .000 & .000 \\
\hline
\end{tabular}

Table 3. Post hoc analysis on students' post-test

\begin{tabular}{|c|c|c|c|c|c|c|}
\hline \multirow{2}{*}{ Source } & \multicolumn{2}{|c|}{ UG.Year1 } & \multicolumn{2}{c|}{ UG.Year3 } & \multicolumn{2}{c|}{ PG } \\
\cline { 2 - 7 } & $\mathrm{F}$ & Sig. & $\mathrm{F}$ & Sig. & $\mathrm{F}$ & Sig. \\
\hline Gamemode * Gender $^{*}$ & .614 & .326 & 1.390 & .323 & .863 & .672 \\
\hline Gamemode * Major & .758 & .424 & 1.379 & .376 & .712 & .461 \\
\hline Gamemode * Personality & 15.700 & .007 & 9.782 & .048 & 18.139 & .024 \\
\hline
\end{tabular}

Table 4. Tests of Between-Subjects Effects

Another one-way ANCOVA was performed on students' post-test results to compare the effect of game mode (collaborative, competitive vocabulary game or traditional learning on the students' vocabulary learning. The students' pre-test results were used as the covariate to exclude the effect of the pre-test on their vocabulary learning. Students' post-test results were used as the dependent variable, and different vocabulary learning methods as the independent variable. From Table 2, it can be seen that learning methods had significant effect on students' vocabulary learning with all significant values being less than 0.05 .

After this, as shown in Table 3, a post-hoc test was conducted on students' post-test results to deeply compare the effects of 
learning methods on promoting students' vocabulary in pairs. From table 2 and 3, it can be observed that students learned vocabulary by the traditional method achieved significantly higher scores than those playing the collaborative vocabulary game, and that those playing the collaborative vocabulary game achieved significantly higher scores than those who played the competitive game.

Table 4 shows significance values of the interaction between personality and game mode. All values here are smaller than 0.05 , which indicates that personality and game mode have a significant interaction to promoting students' vocabulary, while there was no significant interaction effect between gender and game mode and between major and game mode with all significance values larger than 0.05 .

To investigate this further, a simple effect test was conducted on the interaction effect between game mode and personality to investigate on each level of one independent variable (game mode), whether the effects of different levels of the other independent variable (personality) on students' vocabulary promotion were significant.

From this analysis we discovered unsurprisingly that in the collaboration mode, students who like to work in a collaborative environment got significant higher post-test results than the others with different personalities with significance values smaller than 0.05 , while there were no significant vocabulary learning differences between students who like to work in a competitive and those who like to work on their own, with significance values larger than 0.05 . However, in the competition game mode, it seems no significant learning differences among all three types of personality.

\subsection{Post Game Questionnaire}

Our post game questionnaire revealed mostly positive attitudes toward the vocabulary learning games. More than $65 \%$ respondents regarded the game as a good use of their study time and more than $70 \%$ that the game would encourage them to study more as well as help them to learn alongside other learning method. In addition to this, a large proportion of respondents, again over $70 \%$, would be interested in using other learning games and would like to use games to learn other subjects. However, the percentage of respondents who would use this game instead of other study methods or would use the game again to learn were not too high with only about $50 \%$ to $60 \%$ answering in the affirmative.

Our post-game survey also revealed significant differences between the two modes of gameplay. On the whole, participants playing in collaboration mode had better impressions of the game than those playing in competitive mode. Only $50 \%$ respondents playing in competitive mode felt that the game helped them learn words, while this number in collaboration group was around $75 \%$. Likewise, only $59 \%$ of participants playing in competitive mode felt that the game made them interested in learning, while $68 \%$ participants in the collaboration group agreed this statement. About $10 \%$ more of participants playing in collaborative mode felt that the game was a good use of study time. More respondents in competition group felt the game would distract them from their study than those in collaboration group with a surprisingly large gap of around $30 \%$. So attitudes where significantly more favourable toward the game when it was played in collaborative mode.

\subsection{Post game interviews}

Post-game interviews revealed more about how our participants felt toward the games. First of all, Our participants advised that the basic mechanics of the game worked well, but that it could be more compelling with better use of graphics, sound and other components found in modern games such a character development and collectable items.

Our participants generally commented that this sort of game could provide a more fun, relaxing and motivating learning environment to supplement traditional learning. Here they felt that both collaborative and competitive game modes could serve to hold their attention, while human contact would also help them develop social skills.

\section{Conclusion}

We have developed a game testing how different modes of competitive and collaborative gameplay influence the effectiveness and user experience of co-located computer-supported vocabulary learning. The results of our evaluation revealed that collaborative games are broadly more effective and preferred by users although some groups of male users preferred competitive games. Competitive games where found to be less effective and neither type of game was quite as effective as traditional learning using cards. However, users expressed positive attitudes towards the games and felt that either type of game could be used in a more relaxing and social way than traditional learning. These results demonstrate the potential of co-located learning

$140 \quad$ International Journal of Computational Linguistics Research Volume 10 Number 4 December 2019 
used to supplement traditional learning and help students improve their overall educational experience and acheivement in the area of vocabulary learning.

\section{References}

[1] Prot, S., McDonald, K. A., Anderson, C. A., Gentile, D. A. (2012). Video Games:: Good, Bad, or Other?, Pediatric Clinics of North America, vol. 59, p. 647-658.

[2] Lee, Y.-K., Chang, C.-T., Lin, Y., Cheng, Z.-H. (2014). The dark side of smartphone usage: Psychological traits, compulsive behavior and technostress, Computers in Human Behavior, vol. 31, p. 373-383, 2014.

[3] Bian, M., Leung, L. (2015). Linking loneliness, shyness, smartphone addiction symptoms, and patterns of smartphone use to social capital, Social Science Computer Review, vol. 33, p. 61-79, 2015.

[4] Provenzo Jr, E. F. (1991). Video kids: Making sense of Nintendo: Harvard University Press, 1991.

[5] Dill, K. E., Dill, J. C. (1999). Video game violence: A review of the empirical literature, Aggression and violent behavior, vol. 3, p. 407$428,1999$.

[6] Craig, P., Roa-Seïler, N., Wang, Z. (2015) . “An Ethnographic Study of Mobile Videogames for English Vocabulary Development in Urban China, In: Paper presented at the Fourth International Conference on Cognitonics, Slovenia, 2015.

[7] Craig, P., Roa-Seïler, N., Rosano, F. L., and Díaz, M. M. (2013). The Role of Embodied Conversational Agents in Collaborative face to face Computer Supported Learning Games, presented at the $26^{\text {th }}$ International Conference on System Research, Informatics \& Cybernetics, Baden Baden, Germany, 2013.

[8] Craig, P., Roa-Seïler, N., Díaz, M. M., Rosano, F. L. (2013). The Role of Embodied Conversational Agents in Collaborative face to face Computer Supported Learning Games, In: Paper presented at the International Conference on System Research, Informatics \& Cybernetics IIAS2013, 2013.

[9] Craig, P., Hu, Q. (2016). Location Based Games to Promote Physical Activity for Chinese University Students, presented at the 1st Conference on Emerging Topics in Interactive Systems, Suzhou, China, 2016.

[10] Avouris, N. M., Yiannoutsou, N. (2012). A review of mobile location-based games for learning across physical and virtual spaces, J. UCS, vol. 18, p. 2120-2142, 2012.

[11] Amory,A., Naicker, K., Vincent, J., Adams, C. (1999).The use of computer games as an educational tool: identification of appropriate game types and game elements, British Journal of Educational Technology, vol. 30, p. 311-321, 1999.

[12] Kinzie, M. B., Joseph, D. R. (2008). Gender differences in game activity preferences of middle school children: implications for educational game design, Educational Technology Research and Development, vol. 56, p. 643-663, 2008.

[13] Prensky, M. (2003). Digital game-based learning, Computers in Entertainment (CIE), vol. 1, p. 21-21, 2003.

[14] Van Eck, R., Dempsey, J. (2002). The effect of competition and contextualized advisement on the transfer of mathematics skills a computer-based instructional simulation game, Educational Technology Research and Development, vol. 50, p. 23-41, 2002.

[15] Lowrie, T., Jorgensen, R. (2011). Gender differences in students' mathematics game playing, Computers \& Education, vol. 57, p. 2244-2248, 2011.

[16] Papastergiou, M. (2009). Digital game-based learning in high school computer science education: Impact on educational effectiveness and student motivation, Computers \& Education, vol. 52, p. 1-12, 2009.

[17] Cagiltay, N. E. (2007).Teaching software engineering by means of computer game development: Challenges and opportunities, British journal of educational technology, vol. 38, p. 405-415, 2007.

[18] Connolly, T. M., Stansfield, M., Hainey, T. (2007). An application of games based learning within software engineering, British journal of educational technology, vol. 38, p. 416-428, 2007.

[19] Ebner, M., Holzinger, A. (2007). Successful implementation of user-centered game based learning in higher education: An example from civil engineering," Computers \& Education, vol. 49, p. 873-890, 2007.

[20] Tüzün, H., Y1lmaz-Soylu, M., Karaku_, T., Onal, Y., K1z1lkaya, G. (2009). “The effects of computer games on primary school students' achievement and motivation in geography learning," Computers \& Education, vol. 52, p. 68-77, 2009.

International Journal of Computational Linguistics Research Volume 10 Number 4 December 2019 
[21] López, J. M. C., Cáceres, M. J. M. (2010). Virtual games in social science education, Computers \& Education, vol. 55, p. 1336-1345, 2010.

[22] Kiili, K. (2007). Foundation for problem based gaming, British journal of educational technology, vol. 38, p. 394-404, 2007.

[23] Liu, T.-Y., Chu, Y.-L. (2010).Using ubiquitous games in an English listening and speaking course: Impact on learning outcomes and motivation, Computers \& Education, vol. 55, p. 630-643, 2010.

[24] Chang, Y.-C., Peng, H., and Chao, H. (2010). Examining the effects of learning motivation and of course design in an instructional simulation game, Interactive learning environments, vol. 18, p. 319-339, 2010.

[25] Brom, C., Preuss, M., Klement, D. (2011). Are educational computer micro-games engaging and effective for knowledge acquisition at high-schools? A quasi-experimental study, Computers \& Education, vol. 57, p. 1971-1988, 2011.

[26] Huang, W.-H., Huang, W.-Y., Tschopp, J. (2010). Sustaining iterative game playing processes in DGBL: The relationship between motivational processing and outcome processing, Computers \& Education, vol. 55, p. 789-797, 2010.

[27] Wang, L. C., Chen, M. P. (2010). The effects of game strategy and preference matching on flow experience and programming performance in game based learning," Innovations in Education and Teaching International, vol. 47, p. 39-52, 2010.

[28] Malone, T. W. (1981). What makes things fun to learn? A study of intrinsically motivating computer games, Pipeline, vol. 6, p. 50, 1981.

[29] Dickey, M. D. (2011). Murder on Grimm Isle: The impact of game narrative design in an educational game based learning environment, British journal of educational technology, vol. 42, p. 456-469, 2011.

[30] Harris K., Reid, D. (2005). The influence of virtual reality play on children's motivation," Canadian Journal of Occupational Therapy, vol. 72, p. 21-29, 2005.

[31] Miller, L. M., Chang, C.-I., Wang, S., Beier, M. E., Klisch, Y. (2011). Learning and motivational impacts of a multimedia science game, Computers \& Education, vol. 57, p. 1425-1433, 2011.

[32] Sung, H.-Y., Hwang, G.-J. (2013).A collaborative game-based learning approach to improving students' learning performance in science courses, Computers \& Education, vol. 63, p. 43-51, 2013.

[33] Sung, H.-Y., Hwang, G.-J. (2013). A collaborative game-based learning approach to improving students' learning performance in science courses, Computers \& Education, vol. 63, p. 43-51, 2013.

[34] Zea, N. P., Sánchez, J. L. G., Gutiérrez, F. L., Cabrera, M. J., Paderewski, P. (2009). Design of educational multiplayer videogames: A vision from collaborative learning, Advances in Engineering Software, vol. 40, p. 1251-1260, 2009.

[35] Ke, F., Grabowski, B. (2007). Gameplaying for maths learning: cooperative or not?, British journal of educational technology, vol. 38, p. 249-259, 2007.

[36] Craig, P., Roa-Seïler, N., Martínez Díaz, M., and Lara Rosano, F. (2013). Assessing the Potential of Colaborative Video Games to Improve Education in La Mixteca Region of Mexico, presented at the Third International Conference on Cognitonics, Slovenia, 2013.

[37] Yu, F.-Y., Chang, L.-J., Liu, Y.-H., Chan, T.-W. (2002). Learning preferences towards computerised competitive modes, Journal of Computer Assisted Learning, vol. 18, p. 341-350, 2002.

[38] Plass, J. L., O’Keefe, P. A., Homer, B. D., Case, J., Hayward, E. O., Stein, M. et al. The Impact of Individual, Competitive, and Collaborative Mathematics Game Play on Learning, Performance, and Motivation.

[39] Chang, L.-J., Yang, J.-C., Yu, F.-Y. (2003). Development and evaluation of multiple competitive activities in a synchronous quiz game system," Innovations in Education and Teaching International, vol. 40, p. 16-26, 2003.

[40] T. B. Council, July 252012.

[41] Knagg, J.. 2014.

[42] Adkins, The 2013-2018 China Digital English Language Learning Market Abstract, AmbientInsight.

[43] E. First, "EF EPI,” 2014.

[44] Jianbin, H., Yuedong, S., Ying, X. (2004). “On the Vocabulary Size for Chinese English Learners, 2004.

$142 \quad$ International Journal of Computational Linguistics Research Volume 10 Number 4 December 2019 
[45] Channell, J. (1988). Psycholinguistic considerations in the study of L2 vocabulary acquisition, Vocabulary and language teaching, p. 83-96, 1988.

[46] Carter, R. (1998). Vocabulary: Applied linguistic perspectives: Psychology Press, 1998.

[47] Allen, V. F. (1983). Techniques in Teaching Vocabulary: ERIC, 1983.

[48] Yip, F. W., Kwan, A. C. (2006). Online vocabulary games as a tool for teaching and learning English vocabulary, Educational media international, vol. 43, p. 233-249, 2006.

[49] Averell, L., Heathcote, A. (2011). The form of the forgetting curve and the fate of memories, Journal of Mathematical Psychology, vol. 55, p. 25-35, 2011.

[50] Dillenbourg, P. (1999). Collaborative Learning: Cognitive and Computational Approaches. Advances in Learning and Instruction Series: ERIC, 1999.

[51] Cooper, J., Robinson, P. (1998). Small-group instruction in science, mathematics, engineering and technology (SMET) disciplines: A status report and an agenda for the future, Journal of College Science Teaching, vol. 27, p. 383-388, 1998.

[52] Smith, B. L., MacGregor, J. T. (1992). What is collaborative learning, 1992.

[53] MacGregor, J. (1990). Collaborative learning: Shared inquiry as a process of reform, New directions for teaching and learning, vol. 1990, pp. 19-30, 1990.

[54] Kuo, F.-R., Hwang, G.-J., Lee, C.-C.(2012). A hybrid approach to promoting students'web-based problem-solving competence and learning attitude, Computers \& Education, vol. 58, p. 351-364, 2012.

[55] Schellens, T., Valcke, M (2005). Collaborative learning in asynchronous discussion groups: What about the impact on cognitive processing?, Computers in Human Behavior, vol. 21, p. 957-975, 2005.

[56] Lipponen, L., (2002). Exploring foundations for computer-supported collaborative learning, In: Proceedings of the conference on computer support for collaborative learning: Foundations for a CSCL community, 2002, p. 72-81.

[57] De Lucia, A., Francese, R., Passero, I., Tortora, G. (2009). Development and evaluation of a virtual campus on Second Life: The case of SecondDMI, Computers \& Education, vol. 52, p. 220-233, 2009.

[58] Hummel, H. G., Van Houcke, J.Nadolski, R. J., Van der Hiele, T., Kurvers, Löhr, H.H.(2011). Scripted collaboration in serious gaming for complex learning: Effects of multiple perspectives when acquiring water management skills, British journal of educational technology, vol. 42, p. 1029-1041, 2011.

[59] Sánchez J. . Olivares, R (2011). Problem solving and collaboration using mobile serious games, Computers \& Education, vol. 57, p. 1943-1952, 2011.

[60] Lou, Y., Abrami, P. C., Spence, J. C., Poulsen, C., Chambers, B.., d'Apollonia, S. (1996). Within-class grouping: A metaanalysis, Review of educational Research, vol. 66, p. 423-458, 1996.

[61] Berg, K. F. (1994). Scripted Cooperation in High School Mathematics: Peer Interaction and Achievement, 1994.

[62] Hron, A., Hesse, F. W., Cress, U., Giovis, C (2000). Implicit and explicit dialogue structuring in virtual learning groups, British Journal of Educational Psychology, vol. 70, p. 53, 2000.

[63] Fischer, F., Bruhn, J., Gräsel, C. . Mandl, H (2002). Fostering collaborative knowledge construction with visualization tools, Learning and Instruction, vol. 12, p 213-232, 2002.

[64] van Bruggen, J. M., Kirschner, P. A., Jochems, W. (2002). External representation of argumentation in CSCL and the management of cognitive load, Learning and Instruction, vol. 12, p. 121-138.

[65] Diziol, D., Walker, E., Rummel, N., Koedinger, K. R. (2010). Using intelligent tutor technology to implement adaptive support for student collaboration, Educational Psychology Review, vol. 22, p. 89-102, 2010.

[66] Chaudhuri, S., Kumar, R., Joshi, M., Terrell, E., Higgs, F., Aleven, V., et al. (2008). It's not easy being green: Supporting collaborative "green design" learning, In: Intelligent Tutoring Systems, 2008, p. 807-809.

[67] Johnson, D., and Johnson, R. (1994). Learning together and alone: Cooperation, competitive, and individualistic," ed: Boston, MA: Allyn and Bacon, 1994.

[68] Johnson, D. W., Johnson, R. T., and Taylor, B. (1993). Impact of cooperative and individualistic learning on high-ability

International Journal of Computational Linguistics Research Volume 10 Number 4 December $2019 \quad 143$ 
students' achievement, self-esteem, and social acceptance, The Journal of Social Psychology, vol. 133, p. 839-844, 1993.

[69] De Jean, J., Upitis, R., Koch, C., Young, J. (1999). The story of Phoenix Quest: How girls respond to a prototype language and mathematics computer game, Gender and education, vol. 11, p. 207-223, 1999.

[70] Moreno, R. (2002). Who Learns Best with Multiple Representations? Cognitive Theory Implications for Individual Differences in Multimedia Learning, 2002.

[71] Campbell, P. B. (1983). Computers in Education: A Question of Access. Access to Computers, 1983.

[72] Zea, N. P., Sánchez, J. L. G., Gutiérrez, F. L., Cabrera, M. J., and Paderewski, P. (2009).Design of educational multiplayer videogames: A vision from collaborative learning, Advances in Engineering Software, vol. 40, p. 1251-1260, 2009.

[73] Triantafyllakos, G., Palaigeorgiou, G., Tsoukalas, I. A. (2011). "Designing educational software with students through collaborative design games: The We! Design\&Play framework, Computers \& Education, vol. 56, p. 227-242, 2011.

[74] Villalta, M., Gajardo, I., Nussbaum, M., Andreu, J. J., Echeverría, A., Plass, J. (2011). Design guidelines for classroom multiplayer presential games (CMPG)," Computers \& Education, vol. 57, p. 2039-2053, 2011.

[75] Hung, H.-C., Young, S. S.-C., Lin, C.-P. (2015). No student left behind: a collaborative and competitive game-based learning environment to reduce the achievement gap of EFL students in Taiwan, Technology, Pedagogy and Education, vol. 24, p. 35-49, 2015. 